\title{
O designer de automóveis: uma revisão histórica sobre a profissão no brasil
}

\section{The car designer: an historical review of the profession in brazil}

Carolina Vaitiekunas Pizarro ${ }^{1}$ Paula da Cruz Landim ${ }^{2}$ 


\section{Resumo}

A profissão de designer automotivo envolve a dedicação ao projeto de um dos mais complexos objetos de uso criados pelo Homem: o carro. O envolvimento de designers brasileiros no projeto de automóveis aconteceu dentro do cenário de industrialização tardia do Brasil. No início o envolvimento de engenheiros e empresários entusiastas do setor resultou nos primeiros projetos de autoria brasileira e com o passar dos anos o interesse das montadoras em atender as particularidades do mercado brasileiro e latino levou à contratação dos primeiros profissionais projetistas do país. O presente artigo é um recorte de uma pesquisa mais ampla desenvolvida em nível de Mestrado na qual a revisão bibliográfica referente ao tema pesquisado desdobrou-se em um amplo estudo sobre a profissão, cujos dados levantados colaboraram para que fosse possivel construir uma revisão histórica sobre a profissão de designer automotivo no Brasil.

Palavras-Chave: Design; Automóveis; Designers; Brasil

\section{Abstract}

The profession of automotive designer involves dedication to the project of one of the most complex objects created by Man: the car. The involvement of Brazilian designers in car design took place in the late industrialization scenario of Brazil. At the beginning the involvement of engineers and car enthusiasts entrepreneurs resulted in the first projects of Brazilian authors and over the years, the interest of manufacturers to meet the particularities of the Brazilian and Latin American market led to the hiring of the first professional designers in the country.This article is an excerpt of a larger research conducted in Master's level in which the bibliographic review of the topic researched has become a large study on the profession, whose data collected helped to make possible to build a historical review of the automotive designer profession in Brazil.

Keywords: Design; Automobile; Designers; Brazil

ISSN: $1808-3129$

Artigo indicado através da organização do evento

${ }^{1}$ NUPECAM-PPG Design-UNESP IDEMi 2015
Bauru, São Paulo, Brasil

caroldipp@gmail.com

${ }^{2}$ NUPECAM-PPG Design-UNESP

Bauru, São Paulo, Brasil

paula@faac.unesp.br 


\section{INTRODUÇÃO}

Muito além de apenas buscar garantir sua sobrevivência, a história da Humanidade foi - e é - permeada pelo ímpeto humano de vencer limites, transpor barreiras, conviver em sociedade e buscar o bem-estar, assim, criou-se e se desenvolveu a cultura material humana, metamorfoseando-se através dos tempos, hábitos e necessidades do Homem e tornando-se ao mesmo tempo objeto de estudo e de ação do design.

$\mathrm{Na}$ esteira de tais criações, muitas foram as soluções encontradas para as mais diferentes necessidades, as quais culminaram na invenção dos mais diversos objetos. Entre tais objetos, a roda influenciou de maneira importante o curso dos acontecimentos, sendo sua invenção tão significativa para a evolução humana, quanto a descoberta do fogo.

As diversas invenções posteriores à roda favoreceram a composição do ambiente e a produção das ferramentas ideais para a criação de um dos mais emblemáticos objetos criados pelo homem: o automóvel. Os avanços em termos de maquinário e velocidade de produção verificados principalmente no período conhecido como Revolução Industrial resultaram em sucessivas transformações no processo produtivo, culminando na incorporação do projeto e do profissional projetista nas produções em série, no aprimoramento de métodos de produção e fabricação, na criação de inovadoras técnicas construtivas e também na pesquisa e desenvolvimento de novos materiais.

O design de automóveis se propõe a desenvolver projetos levando em conta tanto os aspectos prático-funcionais do objeto como ergonomia, segurança, conforto e desempenho, quanto os aspectos subjetivos e simbólicos do mesmo, os quais sejam a identificação emocional, adequação ao gosto do consumidor e materialização dos desejos dos mesmos.

Atualmente, as empresas do setor investem no potencial de crescimento do mercado nacional e buscam, por meio do design, produzir de acordo com os anseios do público brasileiro, o que não significa sobremaneira isentar-se do desenvolvimento de design e inovação com potencial global. É cada vez maior o reconhecimento de que fatores como as necessidades locais, a diversidade dos diferentes mercados nos quais tais companhias atuam, e principalmente no caso do Brasil, o peso que a filial brasileira tem para os negócios da marca, desenham cenários mais complexos no que tange à produção de projetos locais e/ou globais.

Enquanto a centralização apresenta suas vantagens, a descentralização de projetos mostra-se mais adequada na busca pela redução do tempo de desenvolvimento quando os produtos destinados aos mercados das subsidiárias sofrem muitas adaptações. Este é o caso do mercado brasileiro, o qual, além de aquecido mercado interno, atualmente apresenta grande influência também na região da América Latina. Desta maneira, têm sido crescentes as solicitações de participação de designers e estúdios de subsidiárias brasileiras no desenvolvimento de projetos globais, até mesmo liderando esses projetos.

O presente artigo é um recorte de um estudo mais amplo, desenvolvido em nível de Mestrado (PIZARRO, 2014) cujo objetivo principal foi conhecer como se dá a prática profissional na indústria automotiva no Brasil. Os dados encontrados na elaboração da revisão bibliográfica apresentada na Dissertação permitiram a cons- 
trução de um histórico detalhado - aqui apresentado de maneira sintética - sobre o surgimento e a consolidação do papel dos designers brasileiros como importantes contribuintes para a fundação das bases e posterior crescimento do design automotivo no Brasil.

\section{MATERIAIS E MÉTODOS}

Esta é uma pesquisa de abordagem qualitativa, cuja ênfase, segundo Sampieri et al (2006, p.7) "não está em medir as variáveis envolvidas no fenômeno, mas em entendê-lo". Na construção da pesquisa, optou-se pela revisão em bibliografia pertinente ao tema, bem como pela análise documental de todos os volumes da revista Quatro Rodas desde o número um publicado no mês de Agosto de 1960, até o número 648 publicado no mês de Outubro de 2013. Os dados encontrados foram organizados em planilhas, separados por décadas e paralelamente foram coletadas e editadas imagens referentes a cada modelo registrado.

\section{A FABRICAÇÃO DE AUTOMÓVEIS E A ATUAÇÃO DO DESIGNER: ASPECTOS HISTÓRICOS}

A invenção e o desenvolvimento do automóvel se inter-relacionam com a própria evolução dos meios de produção e da sociedade. Não há, portanto, uma data exata, a qual possa ser tomada como marco inicial da produção deste objeto. 0 surgimento do automóvel deu-se a partir de uma série de revoluções técnicas empreendidas no decorrer dos anos, resultantes, em sua maioria, de invenções aliadas a uma série de procedimentos empíricos os quais resultaram em novas descobertas.

Foi a partir do período da Revolução Industrial que tais descobertas resultaram em novas criações e ganharam velocidade.

Ao longo deste período, como ressalta Vieira (2008, p. 96-130), tiveram papel significativo o surgimento dos trens e alguns veículos à vapor; a criação e construção das ferrovias; os primeiros motores à combustão interna e externa; a descoberta de potencialidades industriais da borracha e seu processo de vulcanização,- patente $\mathrm{n} \cong 3.633$ de Charles Goodyear em 1844 -, dando origem aos pneus; os diversos estudos e testes com combustíveis; a fabricação do aço; o revestimento asfáltico criado por Edward J. de Smedt, datado de 1870 e aprimorado pelo inventor em 1872, e o motor à gasolina.

Tais invenções - entre muitas mais - foram imperativas para o surgimento dos primeiros automóveis e das primeiras indústrias fabricantes de veículos. Neste cenário, a origem do profissional hoje conhecido como designer de automóveis remonta à origem do profissional desenhista industrial empregado pela indústria, o qual começou a surgir a partir do período da Revolução Industrial, no qual a inserção da mecanização nos meios de produção foi acompanhada por uma radical divisão do trabalho. Tal mudança organizacional, de acordo com Forty $(2007$, p.43) ocorreu no século XVIII, na qual um dos aspectos que marcaram a transição da fabricação oficinal para a industrial foi o uso de projetos ou modelos de base para a produção 
seriada. Foi neste contexto que se constituiu a profissão de desenhista industrial ou designer, como ressalta Schneider:

A criação dos objetos - trabalho mental - e a sua produção - trabalho das máquinas - tornaram-se atividades distintas. Aqui, na divisão industrial do trabalho, surgiu a moderna atividade de projeto de produtos, surgiu o design industrial. Já não eram os artesãos que produziam a maioria dos objetos e lhes davam forma (SCHNEIDER, 2010, p.16).

O autor ainda destaca que, como resultado desta mudança, os empresários donos de manufaturas ou fábricas "[...] encarregavam os então denominados "projetistas" ou "fazedores de amostras" - também chamados de "desenhistas" ou "modeladores" - de desenvolverem os produtos que depois seriam produzidos pelas máquinas". A formação destes profissionais ocorria em parte nas escolas de desenho ou de arte, ou os mesmos obtinham seus juízos de gosto no entorno das academias de arte. Aproximadamente em 1800, o trabalho de projetista tornou-se então uma profissão independente e, por volta de 1850, o termo "designer" já era utilizado para fazer referência a este profissional. Como Cardoso reflete:

Entre 1850 e 1930 aproximadamente três gerações de novos profissionais - alguns já apelidados de "designers" - dedicaram seus esforços à imensa tarefa de conformar a estrutura e a aparência dos artefatos de modo que ficassem mais atraentes e eficientes. Sua meta era nada menos que reconfigurar o mundo com conforto e bem estar para todos (CARDOSO, 2012, p.16).

Em pouco tempo, os empresários da indústria perceberam que o custo envolvido na criação de um padrão ou o modelo de base - ou mesmo a compra de tal padrão/modelo de um designer independente - era único e sua possibilidade de reprodução ilimitada, o que também garantia às empresas grande lucratividade. De acordo com Vieira (2010, p.176-334) entre o final do século XIX e início do século XX, muitas das marcas atualmente conhecidas já haviam sido lançadas e contavam com inúmeras patentes como fabricantes de peças, motores e mesmo automóveis, entre elas a Peugeot, Rolls-Royce, Bugatti, Renault, Fiat, Ford e Mercedes.

Os primeiros projetos de veículos não envolviam um profissional desenhista industrial dedicado ao design do carro. Em geral estavam envolvidos no projeto, além de engenheiros e do empresário fabricante, os próprios trabalhadores das empresas montadoras - ou prestadores de serviço de oficinas autônomas - com amplo conhecimento técnico formado a partir da prática adquirida no dia-a-dia da fabricação de peças e componentes para o carro. Sob a supervisão dos engenheiros, os montadores encaixavam as peças fornecidas de maneira artesanal, ajustando suas medidas, buscando assim alinhar cada peça na composição do veículo como um todo.

Em verdade, foi após a disseminação das técnicas de produção em massa e do consequente aumento do consumo, que a forte concorrência entre as empresas - incluídas as fabricantes de automóveis - forçou melhorias na produção e no projeto, trazendo como consequência a especialização dos profissionais envolvidos, favorecendo a formação do profissional designer, como Schneider (2010, p.94) complementa: "Com a crescente pressão da concorrência, por exemplo, no setor automobilístico, o design tornou-se um fator importante para a diferenciação dos concorrentes no mercado". 
No decorrer do século XX, notadamente o período entre e pós-Guerras, o que se presenciou foi uma ampla gama de invenções ou novas aplicações para as tecnologias disponíveis. Neste cenário, também a especialização da mão-de-obra consolidou o papel do profissional projetista ou designer, a qual teve grande impulso no início da crise econômica mundial que resultou na recessão de 1929, uma vez que os fabricantes reconheceram a importância de uma produção diferenciada e uma configuração consistente para incrementar as vendas. De acordo com Heskett:

Foi nesse contexto econômico que surgiu uma nova geração de desenhistas industriais. Eles vinham de diversas formações e seus métodos e realizações eram muito variados, mas o resultado de seu trabalho, o design, seria reconhecido como característica essencial da atividade comercial e industrial, um elemento de especialização dentro da divisão de trabalho implícita na produção e nas vendas em massa (HESKETT, 2006, p.107).

Nos anos que se seguiram, sendo o design um dos principais fatores responsáveis pelo equilíbrio entre os interesses empresariais e as necessidades dos usuários, segundo Löbach (2001, p.121) sua aceitação dentro das empresas se deu principalmente após 1945, quando as mesmas de fato começaram a estruturar os próprios setores de design.

\section{O DESIGN E OS DESIGNERS AUTOMOTIVOS NO BRASIL: DO INÍ- CIO À ATUALIDADE}

A partir do emprego dos primeiros profissionais projetistas, a profissão se estabeleceu e se adaptou às constantes mudanças dentro do setor industrial e do ambiente sociocultural, firmando-se como um campo de atuação de extrema relevância também no Brasil. Atualmente, estão sob a tutela do designer - com diferentes graus de autonomia - não apenas a atividade projetiva, mas também empreender junto às demais áreas o desenvolvimento das diferentes fases do projeto, alinhando expectativas da empresa e do usuário na produção do produto.

No Brasil, a produção e comercialização de veículos desde a instalação das primeiras indústrias vêm se destacando e com o passar dos anos construiu o cenário para o surgimento de projetos de design automotivo no país.

Importa ressaltar o fato de que muitas das empresas iniciaram suas atividades no país a partir de espaços alugados para a receptação e revenda de veículos montados, ou ainda, para a receptação de veículos completamente desmontados - sistema este denominado pela sigla CKD, empregada em substituição ao termo em inglês Completely Knocked Down - para montagem no Brasil, visando à redução de custos. Portanto, em um primeiro momento não se instalaram fábricas. Neste sentido destaca Camargo:

A instalação da indústria automotiva no Brasil foi condicionada pela forma como ocorreu a expansão da indústria internacional desde seu início, ou seja, num primeiro momento, a expansão feita via exportação de veículos montados e, principalmente, de veículos na forma CKDs; num segundo momento, investimentos diretos com a instalação de unidades produtivas verticalizadas (CAMARGO, 2006, p.120).

Até a Primeira Guerra Mundial, o Brasil apenas importava automóveis montados. 
Nos anos que se seguiram, as condições brasileiras, tais como o baixo custo de produção, mão-de-obra barata e mercado consumidor pouco explorado favoreceram os primeiros investimentos no Brasil. A partir de então, as matrizes das montadoras de grande volume verificaram no Brasil um mercado promissor e al potencial, fez com que muitas empresas instalassem estúdios de design em suas subsidiárias brasileiras, empregando os primeiros designers do ramo. Também as empresas multinacionais de iniciativa nacional - tais como a Gurgel, Puma e Troller - instaladas no país ajudaram a construir - e manter - um dos mais importantes e lucrativos setores industriais brasileiros, capacitando profissionalmente um grande contingente de mão-de-obra, gerado empregos, design e inovação. Paralelamente à produção industrial, outros tantos designers brasileiros - notadamente a partir do fim da década de 1960 - estiveram empenhados em desenvolver projetos inovadores. A criação e desenvolvimento destes modelos chamados de "fora-de-série" eram, em sua maioria, fruto da união de designers, engenheiros e empresários brasileiros entusiastas do automobilismo - Gurgel, Puma, Aldo Auto Capas/Miura, Lafer, Santa Matilde, Renha, L' automobile, Furglass, Glaspac entre outras, surgiram nesse contexto.

As criações desses projetos tinham como objetivo preencher lacunas na comercialização de alguns modelos, os quais não eram produzidos no Brasil - esportivos, por exemplo - e cujos usuários ou empresas interessados enfrentavam grandes dificuldades na importação de peças e veículos montados, devido às medidas restritivas impostas pelo governo brasileiro inicialmente na década de 1950 - com o objetivo de proteger a incipiente indústria instalada no país - e posteriormente tornando ainda mais fortes as restrições aos importados na década de 1970, visando segurar o desenvolvimento tecnológico dos modelos produzidos pelas multinacionais no Brasil, para manter os preços praticados.

Como consequência surgiram novas experimentações em projetos e produções de veículos fora-de-série, refletidos na produção de réplicas de modelos famosos, buggies produzidos em fibra de vidro, além da multiplicação de profissionais especializados na modificação de veículos originais de fábrica. Essas soluções nacionais ganharam força na década de 1980 e, em um curto espaço de tempo, várias empresas surgiram dedicadas à criação, produção ou modificação de veículos - Dacon, Envemo, Souza Ramos, Sultan, Engerauto, Sorana, Caltabiano, entre outras - buscando atender à demanda por modelos diferenciados não suprida pelas indústrias aqui instaladas. Percebe-se, portanto, que a criatividade e atuação dos primeiros designers automotivos brasileiros não se restringiram às grandes indústrias, antes, se fez da força de vontade e comprometimento com a produção de projetos bem executados e inovadores, independente dessa atuação se fazer dentro ou fora das multinacionais e sendo o projeto feito sob encomenda, executado por gosto pessoal ou pelo ímpeto empreendedor de tentar consolidar no país uma indústria automobilística genuínamente nacional. No que se refere à atuação dentro da indústria automotiva, ao longo do tempo, os estúdios das subsidiárias brasileiras de grandes empresas mostraram sua capacidade criativa e conquistaram espaço diante dos desafios econômicos e mercadológicos que se apresentaram no setor, sendo cada vez maior a participação por parte dos estúdios brasileiros no desenvolvimento de projetos globais os quais são comercializados ao redor do mundo. 
Nas páginas seguintes, divididos por décadas, serão apresentados brevemente dados sobre a atuação dos designers dentro do cenário automotivo nacional.

\section{DÉCADAS DE 1920,1930 E 1940}

A primeira linha de montagem instalada no Brasil, no ano de 1919, foi inaugurada pela Ford - Figura 1 - a qual produzia o Modelo T partir do sistema CKD - na época não havia o emprego de profissionais projetistas brasileiros. Neste sistema, as partes do veículo chegavam ao Brasil desmontadas juntamente à documentação de orientação para os procedimentos de montagem do veículo, de acordo com os padrões Ford.

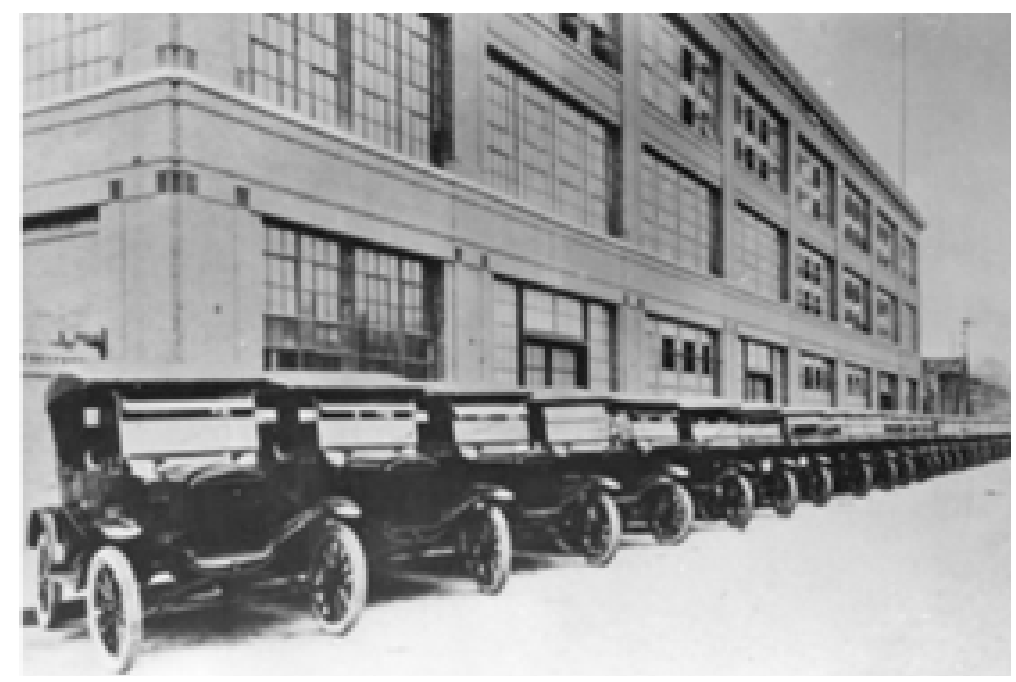

Figura 1: Primeira fábrica montadora da Ford no Brasil - Saldiva et al.(2011)

\section{DÉCADA DE 1950}

Os anos de 1950 podem ser considerados um marco para a história da indústria de automóveis no Brasil, década a qual, de acordo com Ono (2004, p.148) "[...] foi marcada por uma grande expansão rodoviária, com a produção em larga escala de automóveis e caminhões". A década de cinquenta testemunhou a consolidação da indústria e a transformação do automóvel em mais do que um útil meio de transporte, também um objeto de desejo generalizado. Naquela época, a publicidade relacionada ao setor ganhou destaque e preencheu revistas com peças gráficas comerciais.

\section{DÉCADA DE 1960}

O interesse crescente da sociedade e dos empresários sobre o automóvel e o potencial do Brasil na criação e produção de veículos estimulou, no ano de 1962, a inciativa do brasileiro Caio de Alcântara Machado em premiar talentos do design automobilístico criando o Prêmio Lúcio Meira de Design Automobilístico para premiar 
novos talentos do design.

Entre os projetos premiados encontrava-se o veículo Itapuan - Figura 2 - de autoria de Márcio Lima Piancastelli, premiação esta que garantiu ao designer a oportunidade de estagiar na empresa Ghia, localizada em Turim, na Itália. De acordo com Ono (2004, p.168), em seu retorno ao Brasil Márcio atuou na Willys Overland e, a partir de 1967 na Volkswagen do Brasil, na qual chefiou a equipe de design - então denominada Estilo - até 1992, período no qual, juntamente a outros designers, foi responsável pelo desenvolvimento de importantes projetos - sendo os grandes marcos os modelos Brasília e SP2 - contribuindo para o desenvolvimento do design no Brasil.

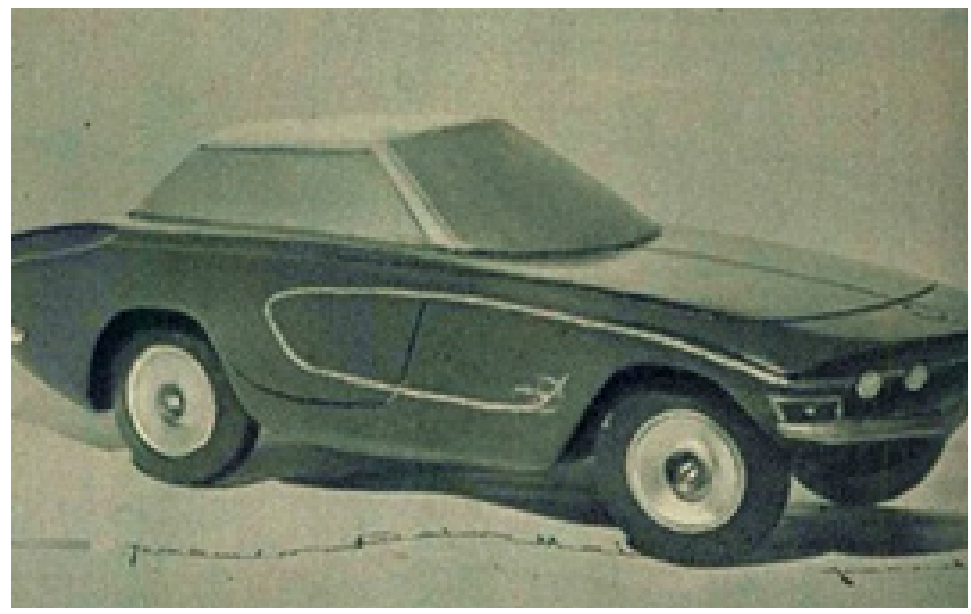

Figura 2: Modelo do projeto Itapuan - Gouveia (1963)

Os designers da época enfrentavam obstáculos para atuar na área ou mesmo se envolver na materialização de projetos nacionais, como destaca Rocha in Pizarro:

Em nenhum momento se verificou qualquer tipo de esforço/interesse, que estimulasse alguma atitude "genuinamente nacional", com desenvolvimento de novas alternativas, ou tecnologias apropriadas. Isso seguiu, de certo modo, a forma de atuação das primeiras empresas instaladas no país (Ford - 1919 / GM - 1925), que só montavam aqui seus carros fabricados nos EUA. Essa condição foi 'determinante' para as ações que se seguiram. A política industrial definida nesse período de origem influenciou o "comportamento" da nossa indústria, sobretudo na área automotiva GEIA ou Grupo Executivo da Indústria Automobilística instaurado em 1956 pelo então presidente Juscelino Kubitschek - para adoção de soluções que não contemplavam as propostas e projetos locais (ROCHA in PIZARRO, 2014, p.55).

Em 1964, a quarta edição do Salão do automóvel foi a ocasião escolhida para sediar paralelamente a segunda edição do prêmio Lucio Meira de Design Automobilístico, o qual foi conquistado pelo projeto Aruanda - Figura 3 - considerado o primeiro carro-conceito do Brasil, de autoria do então estudante de arquitetura da FAU USP Ari Antônio da Rocha. 

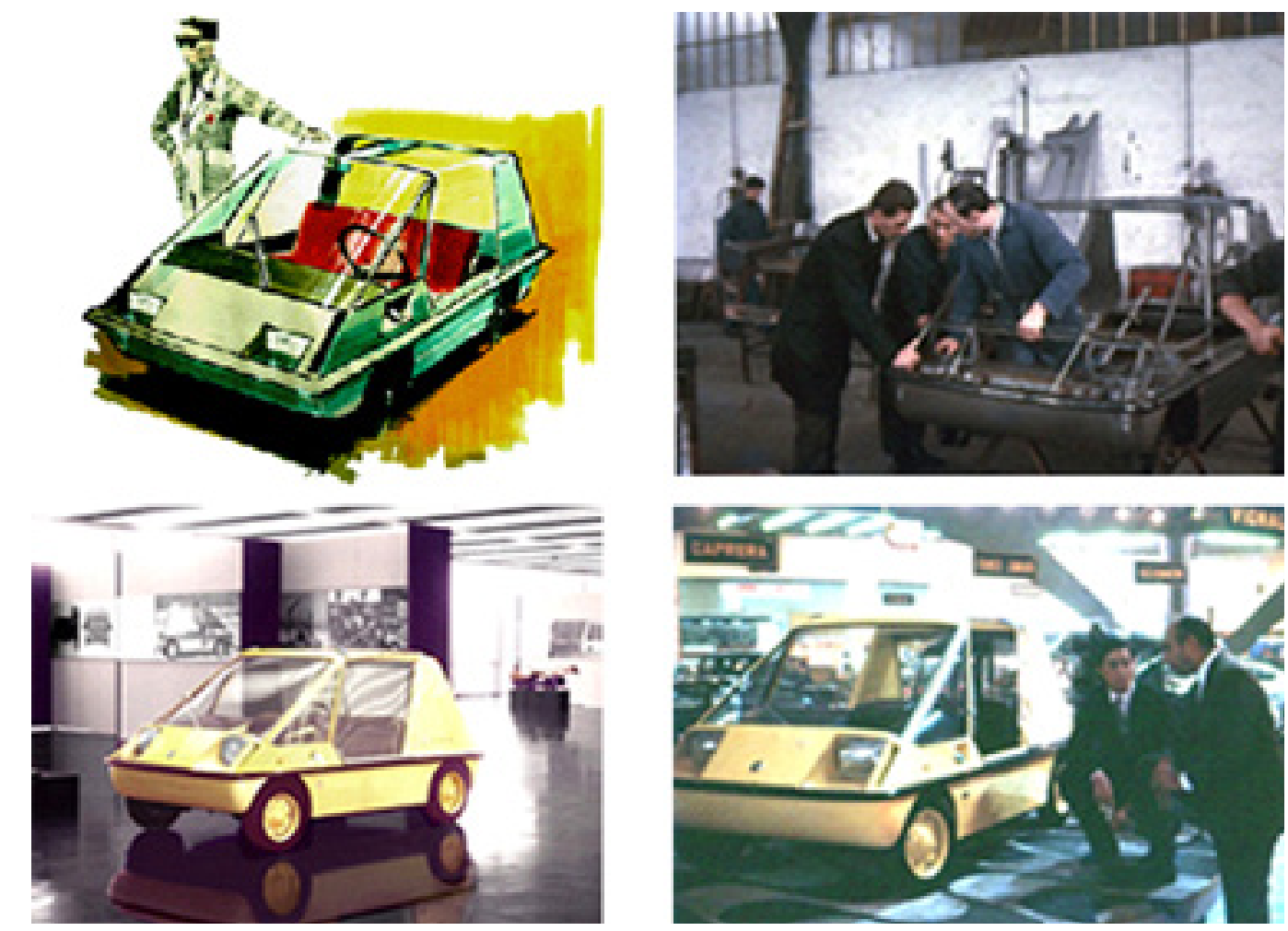

Figura 3: O projeto Aruanda Edição fotográfica de Pizarro (2014) a partir de imagens do acervo pessoal do designer Ari Rocha

O sucesso de seu projeto garantiu que, em novembro do ano seguinte - 1965 - o protótipo fosse construído na Carrozzeria Fissore, a convite do proprietário Mario Fissore, na Itália, recebendo o prêmio de proposta mais inovadora do 47은 Salone Internazionale dell'Automobile de Turim. Embora se tratasse de um grande avanço em termos de design automotivo, o Aruanda também não obteve o apoio necessário para chegar ao mercado e aos usuários.

Além de Ari Rocha, outros designers contribuíram para que - apesar das dificuldades - projetos marcantes de autoria brasileira chegassem às ruas. Um dos desenvolvimentos no qual Ari atuou junto a Rigoberto Soler, compondo sua equipe de projeto, foi do veículo inicialmente nomeado Uirapuru, um protótipo do que seria o primeiro carro esportivo fabricado no Brasil. Mais tarde renomeado e lançado como Brasinca 4200 GT - Figura 4 - o veículo foi desenhado e desenvolvido no Brasil pela equipe chefiada por Soler - então chefe do departamento de engenharia de produtos da Brasinca.

O Brasinca 4200 GT foi o primeiro carro esporte totalmente criado e desenvolvido no Brasil a partir de mecânica Chevrolet, com vistas a atender certa faixa do mercado carente de veículos deste tipo, frente à dificuldade de importação. Cerca de um ano após o lançamento do veículo, a Brasinca não mais manteve a produção em função dos altos custos, mas o modelo continuou a ser construído pela STV, empresa de projetos da qual Rigoberto Soler era diretor na época. Até 1967 foram fabricados 77 exemplares, incluídos os três conversíveis produzidos. 

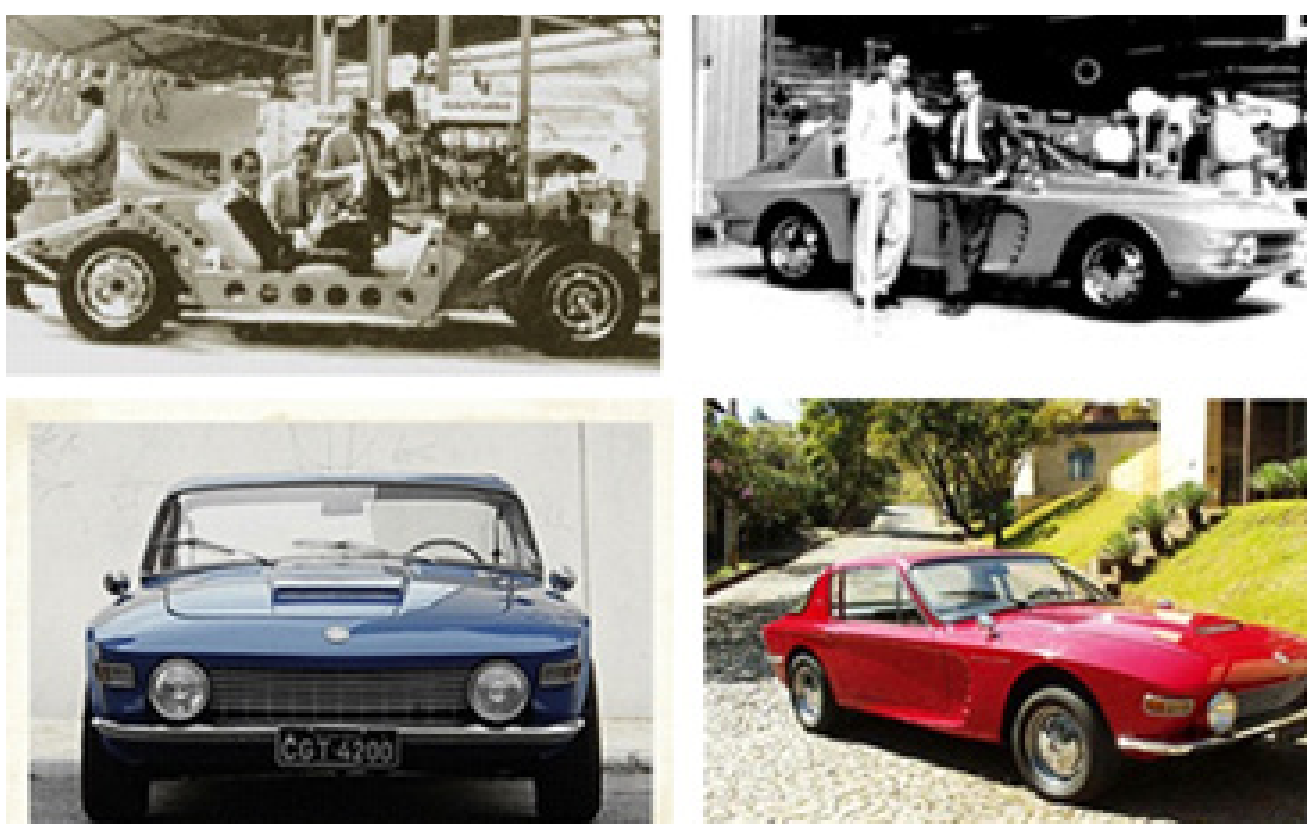

Figura 4: Brasinca 4200 GT - Edição fotográfica de Pizarro (2014) a partir de imagens do acervo pessoal do designer Ari Rocha

Já em 1965, o empresário e engenheiro João Amaral Gurgel, empresário dedicado ao desenvolvimento de projetos inovadores para a área automobilística, apresentou à revista Quatro Rodas o protótipo de um carro popular, e, na ocasião, a publicação sentenciava em reportagem denominada "Carro barato esbanja com 16 marchas", presente na edição de Outubro de 1965, que o veículo - nomeado pelo sobrenome do seu criador, Gurgel, Figura 5 - poderia vir a ser o verdadeiro carro popular brasileiro.

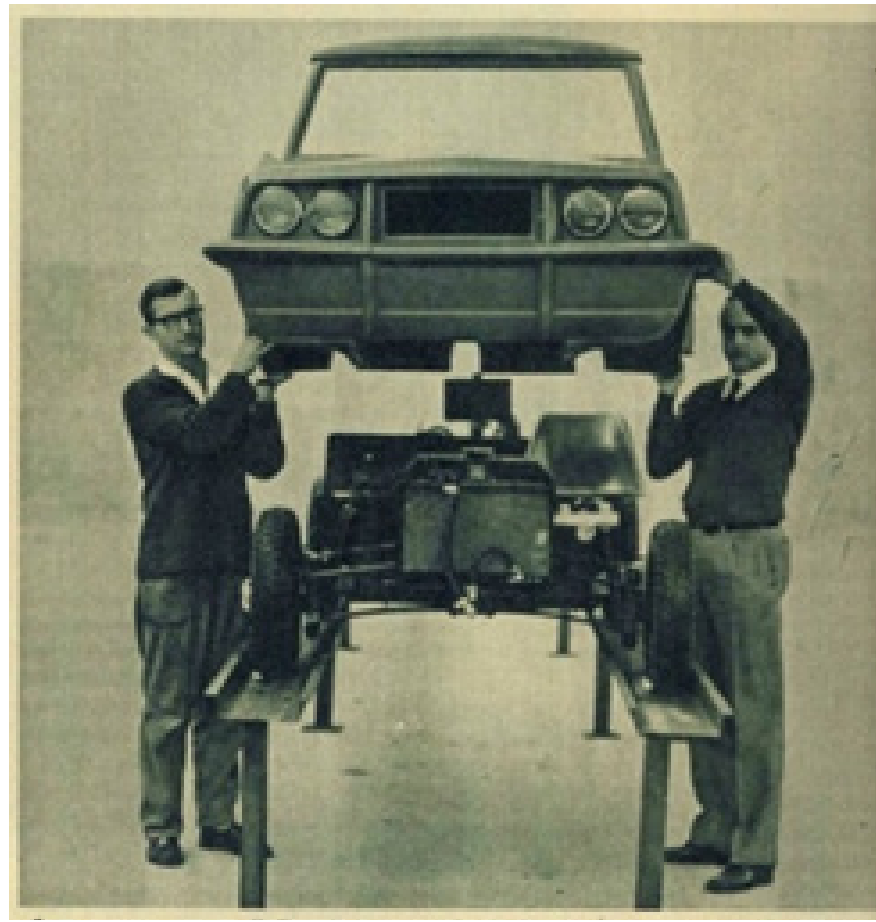

Figura 5: Um dos primeiros protótipos do Gurgel - Ribeiro (1965)

Ainda na década de 1960, o Grã Turismo brasileiro GT Malzoni - Figura 6 - chamou a atenção da mídia e do público em 1964. O veículo foi projetado inicialmente 
para corridas e produzido em um galpão na fazenda de Genaro "Rino" Malzoni - empresário do setor alcooleiro de Matão (SP) e entusiasta do automobilismo.

O sucesso do GT Malzoni garantiu que o mesmo viesse a ser fabricado pela DKW-Vemag em 1966, sendo também denominado DKW Malzoni e produzido com base no protótipo criado por Rino Malzoni e sua equipe.

A equipe que apoiava Rino era composta por Anísio Campos - ex-piloto de corridas da Vemag, Simca, Willys e Dacon que, ao fim das corridas com equipes oficiais de fábricas e conhecendo Rino Malzoni, dedicou-se a projetar veículos, aperfeiçoando traço e técnica com base em anos de experiência - com o apoio em engenharia de Jorge Lettry - profissional especialista em mecânica que foi Chefe do Departamento de Competições da Vemag e com ampla experiência em corridas e preparações de veículos - e Marinho ex-piloto também com ampla experiência na área.

O DKW Malzoni, produzido em 1966, daria origem, meses depois, ao Puma DKW.
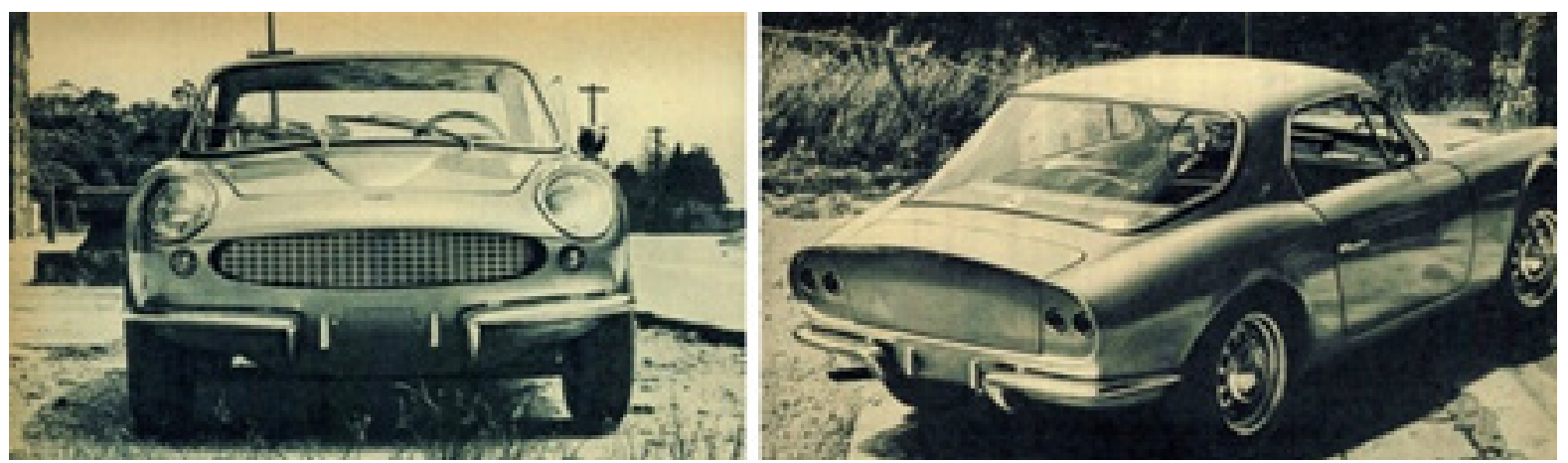

Figura 6: Malzoni GT fabricado pela DKW-Vemag - Ribeiro (1966)

No final da década, 1960 Rino Malzoni se associou a Luís Roberto Costa, José Luíz Fernandes, Jorge Lettry e Milton Masteguin, fundando a fábrica Puma, com Anísio Campos como designer responsável pelo design dos veículos.

Em 1968, foi lançado o Puma GT - Figura 7 - primeiro modelo a ser produzido pela marca Puma, sendo inicialmente fabricado a partir de chassi e mecânica da marca DKW. Por essa razão, os modelos fabricados neste período são também denominados Puma DKW.

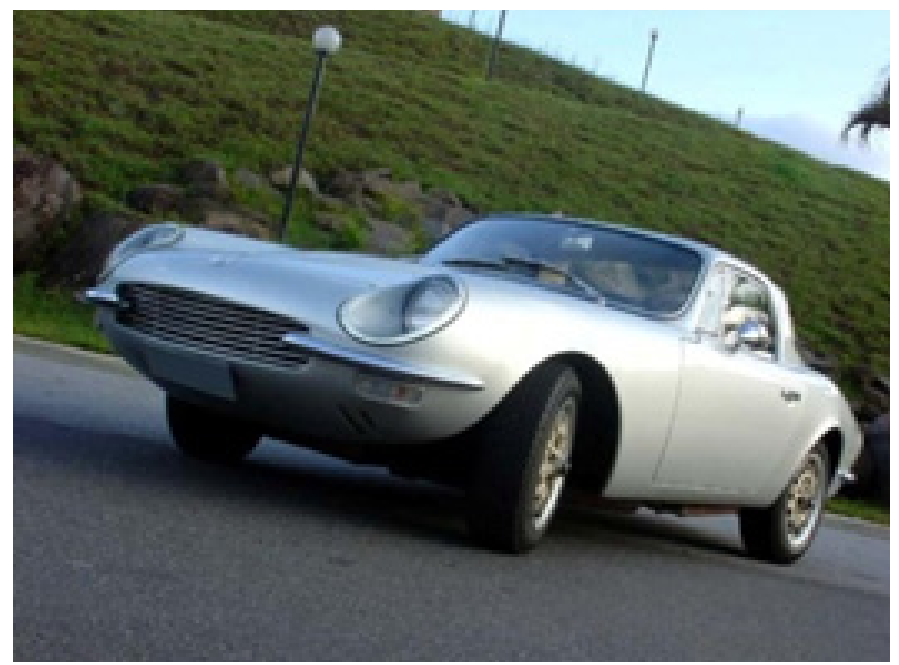

Figura 7: Puma GT ou DKW primeiro a ser produzido em 1967 com mecânica DKW-Vemag - Auto garage (2011) 
Ao fim das atividades da Vemag, o Puma GT passou a ser montado sobre chassi Karmann Ghia e mecânica Volkswagen, com novo design e designação GTE a partir de 1969, um projeto de grande sucesso - Figura 8.

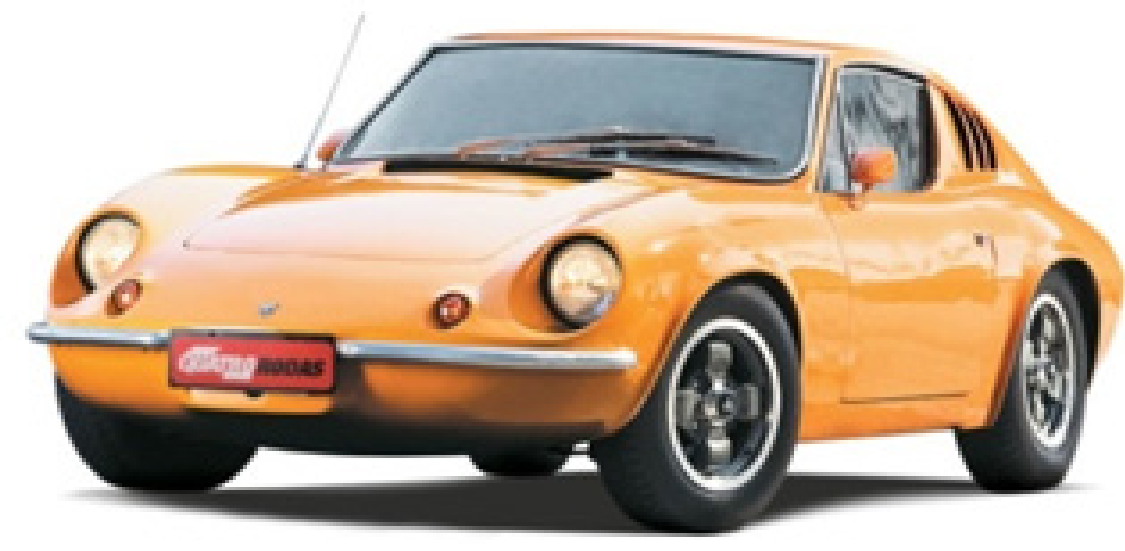

Figura 8: Puma GTE - Pereira; Castanho (2008)]

Paralelamente às inciativas brasileiras, as indústrias multinacionais continuavam a crescer e a ampliar as opções de modelos de veículos ofertados ao mercado nacional.

\section{DÉCADA DE 1970}

A década de 1970 assistiu à ampliação progressiva de atuação das multinacionais e no que se refere às iniciativas de projetos brasileiros, esta década foi marcada por criações e novos desenvolvimentos tanto na indústria quanto paralelamente à mesma.

A difusão das técnicas de produção em fibra de vidro e o aprimoramento da prática de projeto permitiram tentativas mais ousadas por parte dos designers e construtores brasileiros.

Para atender a faixa do mercado carente de veículos diferenciados frente à proibição de importação vigente, verificaram-se nos anos iniciais da década de 1970 uma confirmação da tendência verificada na década anterior: as produções dos veículos conhecidos como fora-de-série.

O termo fora-de-série foi empregado para designar os veículos não produzidos em série por grandes fábricas. Tais modelos eram construídos a partir de técnicas muitas vezes artesanais e produzidos por pequenos fabricantes para atender a nichos de mercado específicos. Assim, surgiram também diversos modelos de buggys, réplicas, esportivos de fibra de vidro, conversíveis, jipes, carros de produção industrial customizados e transformados.

A produção destes veículos fortaleceu-se na década de 1970, consolidou-se na década de 1980 perdurando até os primeiros anos da década de 1990 - quando a abertura do mercado à importações reduziu drasticamente a procura por estes veículos, tornando-os relíquias.

Assim, chegaram ao mercado, em volume e variedade crescente, esportivos como o o Miura, de 1977, com mecânica VW produzido pela Aldo Auto Capas de Por- 


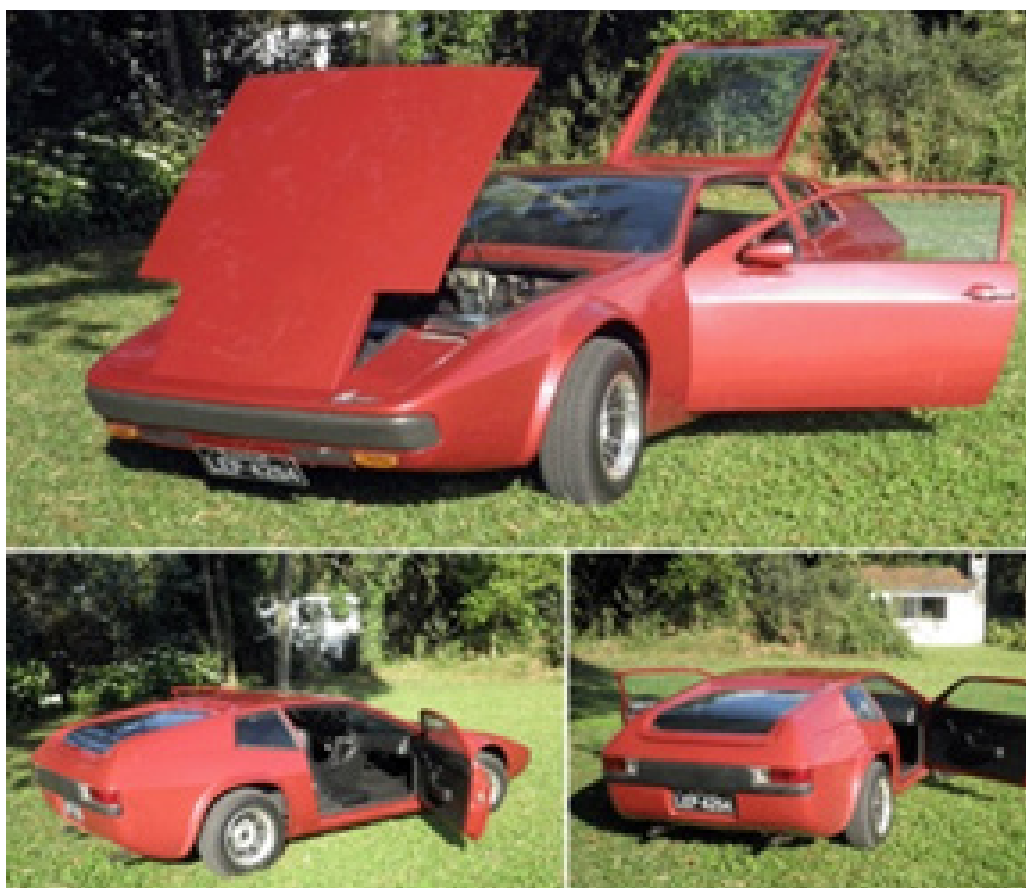

Figura 9: Miura 1977 desenvolvido pela empresa Aldo Auto Capas - Siciliano (2013)

Dentro das grandes indústrias, o design e os designers brasileiros começavam a conquistar algum reconhecimento. Um exemplo foi o desenvolvimento dos modelos Volkswagen SP2 e Brasília - lançados em 1972 e 1973 respectivamente.

De acordo com Ono (2004, p. 170-172), ambos os projetos foram coordenados por Márcio Lima Piancastelli com atuação de José Vicente Novita Martins e George Yamashita Oba, sendo o design dos veículos completamente desenvolvido no Brasil. A autora ainda destaca o amplo sucesso do Brasília, que superou em vendas o Volkswagen Sedan 1200, o "Fusca" ao alcançar a marca de 1.064.416 unidades vendidas de 1973 à 1981, sendo também exportado para outros países. O SP2 - Figura 10 - foi trabalhado sobre a plataforma do Variant e partiu de um desejo do então presidente da Volkswagen, Rudolph Leiding, o qual gostaria de ver no portfólio da empresa um modelo esportivo.
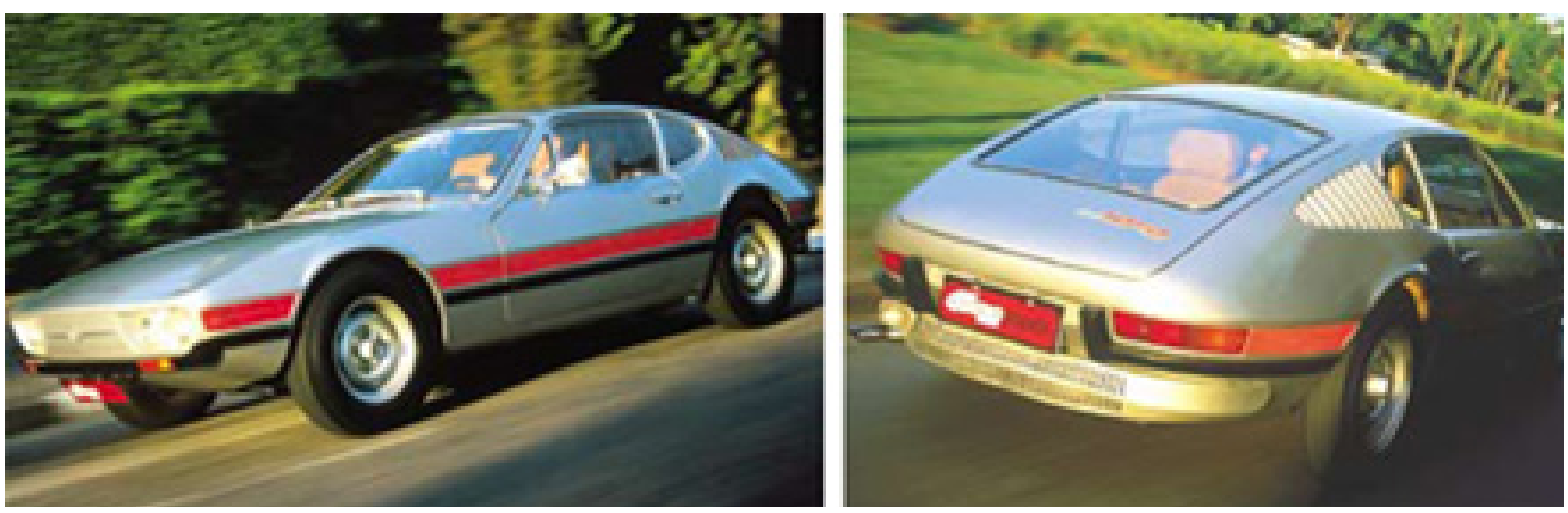

Figura 10: Volkswagen SP2: o esportivo foi o primeiro projeto brasileiro da Volkswagen - Berezovsky (2002) 


\section{DÉCADA DE 1980}

Na década de 1980 a Fiat, então atuante no Brasil desde 1976 passou a lançar variados modelos e a competir com força no mercado nacional junto às já grandes Volkswagen, Ford e GM. Os projetos de modelos fora-de-série atingiram seu auge e até mesmo modelos pick-ups eram modificados.

Também merece destaque o Mini Dacon ou Dacon 828 (1982) - Figura 11 - projetado pelo designer Anísio Campos e pelo engenheiro Paulo Goulart - um projeto de veículo urbano produzido pela Dacon, revendedora da Volkswagen de SP.
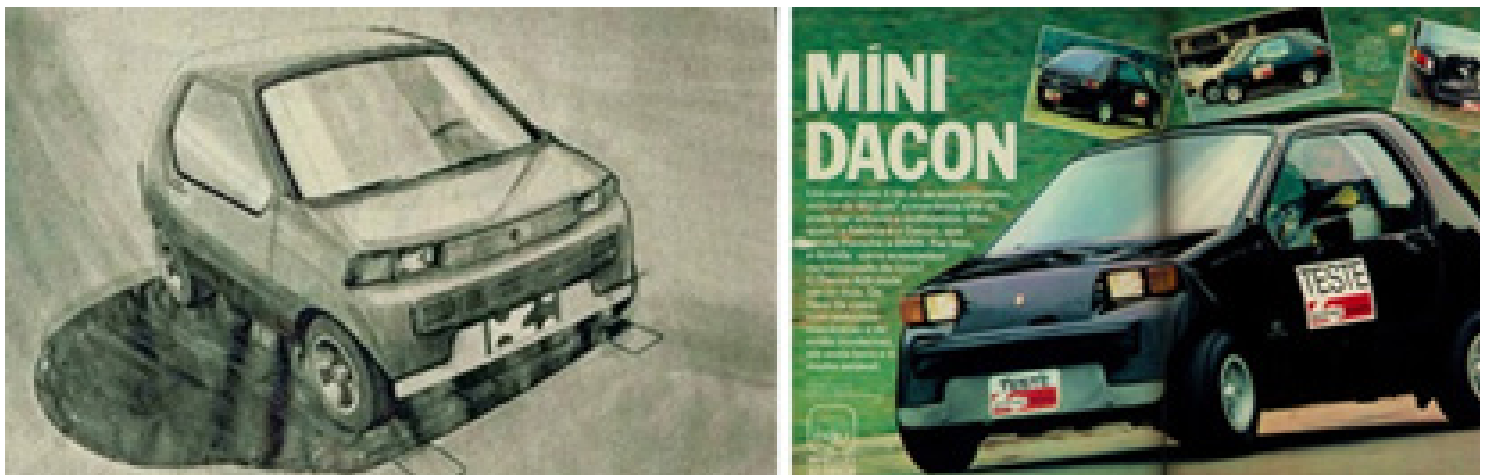

Figura 11: Mini Dacon de autoria de Anísio Campos - Camanzi; Yoshioka (1982)

Modelos de sucesso das grandes montadoras também foram lançados nesta década, como o Volkswagen Gol, Ford Escort XR-3 e o Fiat Uno.

Entre as produções nacionais, em 1988, foi lançado também o Gurgel BR 800 - Figura12. O modelo foi o primeiro carro completamente desenvolvido no Brasil. Até então, a Gurgel fabricava a partir de componentes Volkswagen, sendo o BR 800 montado a partir de conjunto mecânico próprio $100 \%$ desenvolvido no Brasil e $60 \%$ das peças e componentes fabricados pela própria Gurgel. O governo brasileiro, na época, visando incentivar produções como essa, estabeleceu uma redução no valor do IPI - $5 \%$ contra os $25 \%$ ou mais para os outros carros - para o modelo popular da Gurgel. Em 1990, tal incentivo foi estendido a todos os carros com motores até um litro, culminando com a produção e entrada da Fiat no mercado dos populares com o lançamento do Uno Mille, postura seguida pelas demais multinacionais.

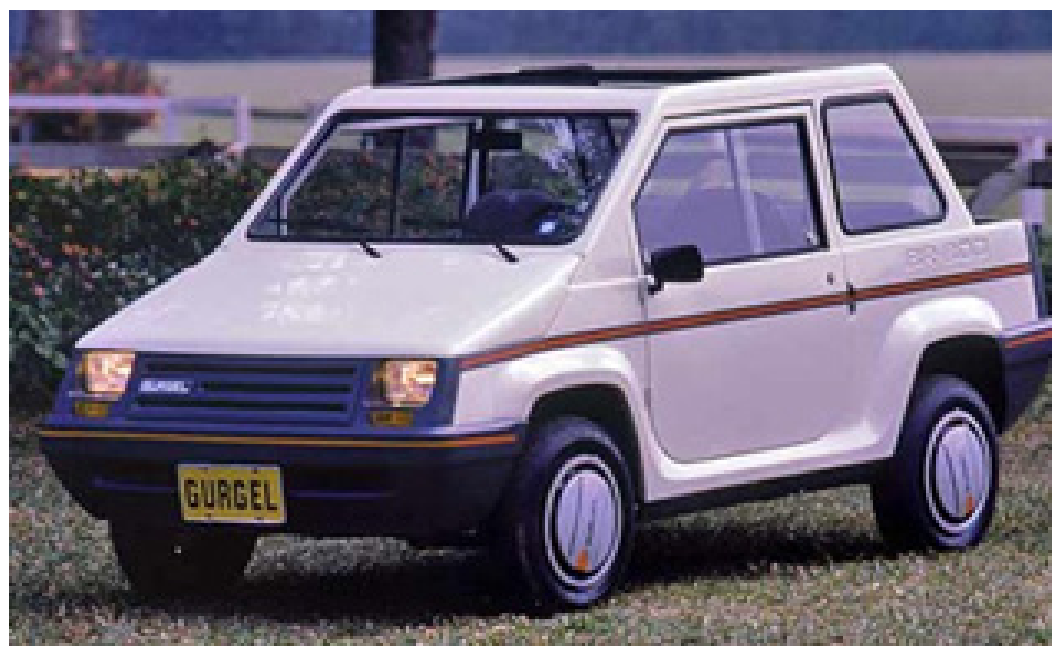

Figura 12: Gurgel BR 800 - Guimarães (2012) 


\section{DÉCADA DE 1990}

Na década de 1990 muitos designers já trabalhavam nos estúdios das subsidiárias nacionais das empresas de grande volume de produção as quais contavam com uma maior participação e influência de designers brasileiros na criação e execução de projetos - ou componentes de projetos. Em Agosto daquele ano, o mercado brasileiro foi aberto às importações e o governo brasileiro permitiu que as indústrias aqui instaladas importassem modelos de seu portfólio produzidos no exterior dentro do limite de $10 \%$ do faturamento com suas exportações originadas no Brasil.

A abertura do mercado aos importados prejudicou de maneira irreversível - e previsível - o mercado dos veículos fora-de-série. A possibilidade vislumbrada pela clientela dos veículos especiais em trazer modelos de sucesso de outros países absorveu seus investimentos, os quais antes eram direcionados a pagar altos valores em veículos exclusivos ou modificados.

No ano de 1992, entre os brasileiros, a Gurgel lançou sua nova proposta de veículo urbano em substituição ao BR-800, modelo que perdeu espaço quando o governo estendeu os incentivos fiscais à produção de veículos com até motorização de até 1 litro, favorecendo a entrada das multinacionais no nicho de veículos populares. Tratava-se do modelo Gurgel Supermini - Figura 13 - o qual, em sua época de lançamento, era o único veículo fabricado pela única montadora nacional. As dificuldades enfrentadas nesse período foram determinantes para o fim da Gurgel, a qual, no ano de 1995, teve sua falência decretada e suas atividades encerradas.
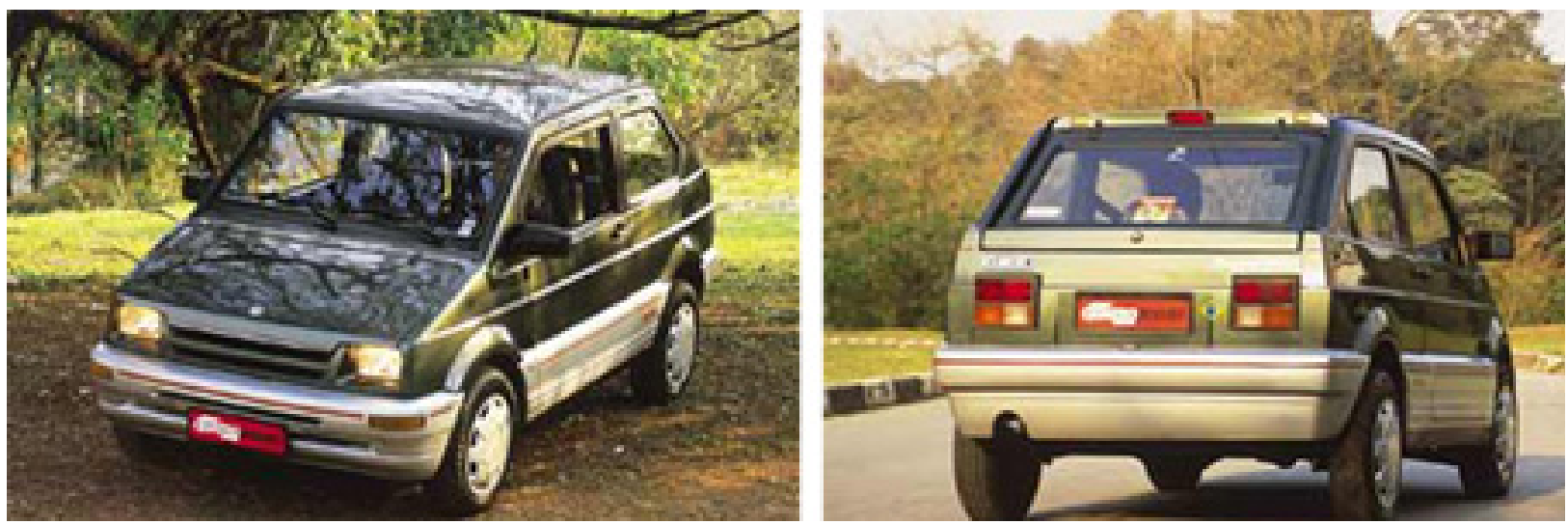

Figura 13: Gurgel Supermin - Berezovsky (2003)

\section{DÉCADA DE 2000}

Nos anos 2000 a atuação dos designers nos estúdios das montadoras já era consolidada e tais estúdios foram sendo ampliados em tamanho e capacidade de desenvolvimento. Muitos projetos comercializados em escala global agora contavam com a participação das equipes de design dos estúdios anexos às subsidiárias brasileiras das empresas multinacionais atuantes no Brasil.

Na sede da Volkswagen, em Wolfsburg no ano de 2008, o designer Luiz Alberto Veiga - atual chefe de Design da Volkswagen do Brasil - fundou o Volkswagen do Brasil Design Corner, um estúdio brasileiro permanente dentro do Centro de Design 
da Volkswagen em Wolfsburg.

Ações como essa e a flexibilidade dos profissionais brasileiros em encontrar soluções criativas para projetos, favoreceu o reconhecimento desses profissionais e o movimento cada vez mais frequente de "exportação" dos designers brasileiros para atuação no exterior, como é o caso dos designers Raul Pires - atuou junto à Bentley e atualmente é Chefe de Design Avançado da Audi AG -, César Pieri - Jaguar -, e dos irmãos João Carlos e Marco Antônio Pavone - atuantes nos estúdios americano e na matriz da Volkswagen, respectivamente.

Também a confiança das matrizes permitiu que projetos como o do Volkswagen Fox - 2003 - fosse completamente desenvolvido pelo estúdio brasileiro da marca, bem como o Novo Ford Ecosport - 2013, figura 14 - projeto global liderado pelo estúdio satélite da Ford no Brasil.
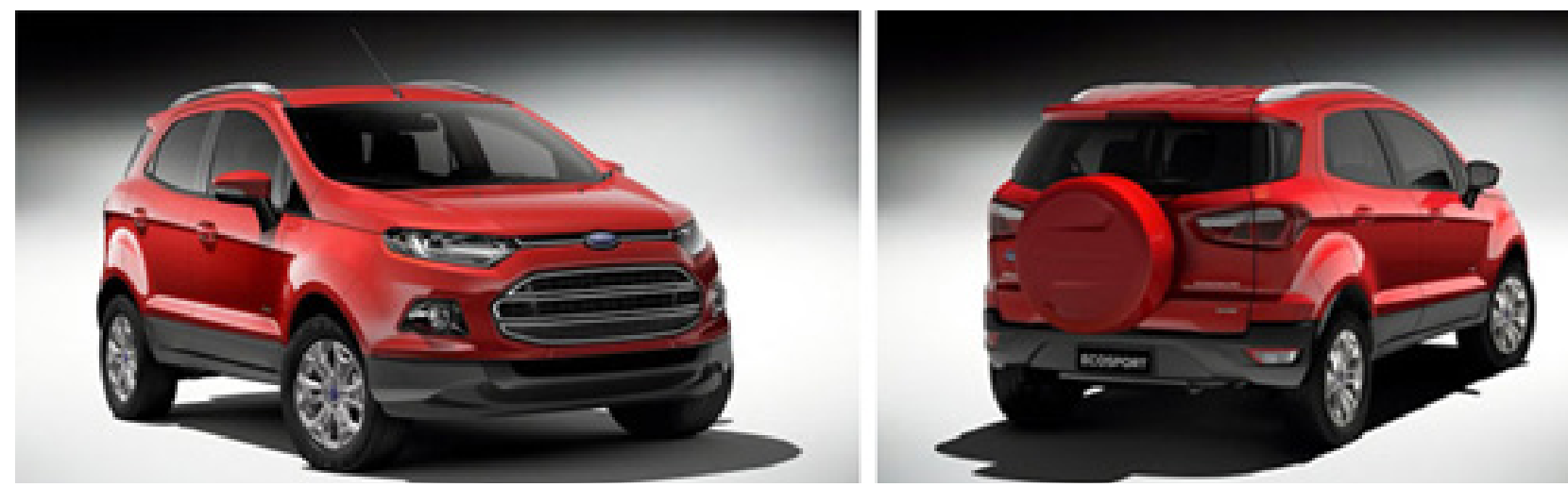

Figura 14: Novo Ecosport 2013 - net car show (2013)

No Brasil, nos dias atuais, além das quatro grandes - Volkswagen, Ford, GM e Fiat - outras empresas como Renault, Peugeot/Citroën, Nissan e Toyota também contam com estúdios de design instalados no país.

Os designers que buscam atuar na área automotiva são geralmente empregados pelos estúdios de design instalados no país, prestando serviços para as montadoras. Entretanto, são também muitos os designers que trabalham nos diversos fornecedores de tecidos, linhas, tintas, couros e plásticos, bem como nas empresas denominadas sistemistas, as quais fornecem componentes principais ou subconjuntos de autopeças já montados às industrias de automóveis. Outros tantos designers optam por seguir a área de maneira autônoma, constituindo empresas próprias voltadas à consultoria e ao desenvolvimento de projetos exclusivos, tais como a Ícon Design coordenada pelos designers Nelson Lopes e Marcio Sartori - e AmoritzGT - fundada e coordenada pelo designer Fernando Morita. Na atualidade, é perceptível, portanto, que a valorização dos profissionais brasileiros é crescente, panorama que traz boas perspectivas futuras de atuação nos âmbitos nacional e internacional.

\section{CONSIDERAÇÕES FINAIS}

Ao fim da pesquisa, constatou-se que a atividade de designer de automóveis surgiu no Brasil tardiamente, nos anos seguintes à instalação das primeiras plantas monta- 
doras e ganhando notoriedade mais especificamente a partir da década de 1960.

O interesse pelo meio automotivo e pela novidade que o carro representava na época, foram alguns dos motivos que levaram aos primeiros experimentos e à concretização das primeiras intenções voltadas ao desenvolvimento de projetos nacionais, resultando no surgimento dos primeiros profissionais brasileiros dedicados a projetos automobilísticos. Condicionadas por fatores de ordem política e econômica, as sucessivas tentativas de se produzir projetos de design automobilístico nacionais sofreram golpes também sucessivos, que por fim, resultaram no enfraquecimento das ações e iniciativas genuinamente nacionais.

Por outro lado, mesmo em cenário desfavorável, os projetos desenvolvidos pelos designers brasileiros seja dentro das grandes montadoras, por intenção pessoal ou sob encomenda, do tipo protótipo ou fora-de-série, são contribuições significativas para a história do design automobilístico nacional e testemunhos da evolução do projeto de design de veículos no país. Merece destaque o envolvimento dos designers pioneiros na produção desses objetos, os quais enfrentando muitos obstáculos abriram o caminho de ação para os futuros designers que nos dias atuais consolidam a profissão como uma das muitas e importantes áreas de atuação para os designers brasileiros.

O reconhecimento em nível global da capacidade projetiva brasileira consquistado na atualidade é, portanto, resultado do envolvimento dos muitos atores que desde a fundação da primeira planta fabril no Brasil até os dias atuais se dedicam a construir para além dos veículos, a própria história do design automotivo no Brasil.

\section{REFERÊNCIAS}

AUTO GARAGEM, 2011, online, Disponível em:< http://autogaragem.wordpress.com/ page/25>.

BEREZOVSKY, S., BARI, M., 2002, "Grandes brasileiros-SP2", Quatro Rodas, online, Disponível em: < http://quatrorodas.abril.com.br/classicos/brasileiros/imagens/0403sp2_abre.jpg>.

BEREZOVSKY, S., 2003, "Grandes brasileiros-Gurgel Supermini, Quatro Rodas, online, Disponível em:< http://quatrorodas.abril.com.br/classicos/brasileiros/conteudo_143471.shtml\#galeria>.

CAMANZI, E., YOSHIOKA, H., 1982, "Mini Dacon”, Quatro Rodas, 5, (262),146, pp.36.

CAMARGO. O.S.,2006, "As mudanças na organização e localização da indústria automobilística brasileira (1996 - 2001)". Tese (Doutorado em Economia) - Centro de Desenvolvimento e Planejamento Regional da Faculdade de Ciências Econômicas, Universidade Federal de Minas Gerais, Belo Horizonte, 323, pp.120. 
CARDOSO, R., 2012, Design para um mundo complex, Cosac Naify, São Paulo, 262, pp. 16.

FORTY, A., 2007, Objetos de desejo - design e sociedade desde 1750, Cosac Naify, São Paulo, 352, pp.43.

GOUVEIA, V.A., 1963, "Estilismo brasileiro começa bem", Quatro Rodas, 1, (30), 116, pp.28.

GUIMARÃES,C., 2012, "Clássico do dia: Gurgel BR800", Auto esporte, online, Disponível em< http://revistaautoesporte.globo.com/Revista/Autoesporte/0,,EMI314594-10142,00.html>.

HESKETT, J., 2006, Desenho industrial, José Olympio, Rio de Janeiro, 228, pp.107.

LOBACH, B., 2001, Design Industrial - Bases para a configuração dos produtos industriais, Edgard Blucher, São Paulo, 206, pp.121.

NET CAR SHOW, 2013, online, Disponível em:<http://www.netcarshow.com/ford/ 2013-ecosport/>.

ONO, M.M., 2004, "Design industrial e diversidade cultural: sintonia essencial. Estudos de casos nos setores automobilístico, moveleiro e de eletrodomésticos no Brasil", Tese (Doutorado em Arquitetura e Urbanismo), Faculdade de Arquitetura e Urbanismo, Universidade de São Paulo, São Paulo, 1.200, pp. 148, 168,170-172.

PEREIRA, F., CASTANHO, C., 2008, "Grandes brasileiros-Puma GTE", Quatro Rodas, online, Disponível em:< http://quatrorodas.abril.com.br/classicos/brasileiros/conteudo_276380.shtml>.

PIZARRO, C.V., 2014, "O designer e a prática profissional na indústria automobilística no Brasil", Dissertação (Mestrado) - Universidade Estadual Paulista Programa de Pósgraduação em Design, Faculdade de Arquitetura, Artes e Comunicação, Bauru, 305 p.

RIBEIRO, H., 1965, "Carro barato esbanja com 16 marchas", Quatro Rodas, 10, (63), 132, pp.90.

RIBEIRO, H., 1966, "Peso pluma em curva de todos os pesos", Quatro Rodas, 4, (69), 180, pp.94-95

SALDIVA, E., CAMILLO, R., VIDOLIN,M., OLIVEIRA, R., 2011, “Ford a montadora mais antiga a operar no país completa 92 anos", online, Disponível em:< https://contagiros.wordpress.com/2011/04/25/ford-montadora-mais-antiga-a-operar-no-paiscompleta-92-anos-de-historia/>. 
SAMPIERI, R.H.; COLLADO, C.H.; LUCIO, P.B., 2006. Metodologia de pesquisa, McGraw-Hill, São Paulo, 624, pp.7.

SCHNEIDER, B., 2010, Design - Uma introdução: o design no contexto social, cultural e econômico, Editora Blücher, São Paulo, 304, pp. 16, 94.

SICILIANO, J., 2013, "Miura, o esportivo nacional", online, Disponível em< http://autoclassic.com.br/site/miura-o-esportivo-nacional-por-joao-siciliano/>.

VIEIRA, J.L., 2008, A história do automóvel: a evolução da mobilidade, 1, Alaúde editorial, São Paulo, 424, pp. 96-130.

VIEIRA, J.L., 2010, A história do automóvel: a evolução da mobilidade, 3, Alaúde editorial, São Paulo, 424, pp. 176-334. 